\title{
Evaluation of the tributaries by influence index on the mid-lower portion of the Nakdong River basin
}

\author{
Shun-Hwa Lee ${ }^{1}$, Seung-Gyu Jung', Seoung-Muk Park', Byung-Dae Lee $^{2^{\dagger}}$ \\ ${ }^{1}$ Department of Environmental Engineering, Yeungnam University, Gyeongsan 38541, Republic of Korea \\ ${ }^{2}$ Department of Health Management, Uiduk University, Gyeongju 38004, Republic of Korea
}

\begin{abstract}
The deteriorating role of Nakdong River due to the Four Major Rivers Project has caused a series of problems, including water pollution, drying streams, aggravation of the hydroecology. Geumho River and Gyeongseong-cheon had a higher concentration index and is believed to impact the water quality of the main stream. The influence index of Geumho River and Nam River between 2015 and 2016, which have a large amount of discharge, was the highest among the tributaries in terms of the load material balance. Showing the highest average concentration and average load in the index assessment, Geumho River is believed to require an intensive management for improving the water quality of the main stream. Furthermore, when the cumulative percentage of the average concentration and average load was compared based on the water quality improvement of the tributaries mixed to Nakdong River, which was set to $60 \%$, Geumho River, Nam River, Topyeong-cheon, and Cha-cheon, which showed the highest ratio in that order, were determined to require a water quality management program as a priority.
\end{abstract}

Keywords: Effect of tributaries, Index assessment, Load mass balance, Water quality of Nakdong River

\section{Introduction}

The Nakdong River water system is one of the largest water resources in South Korea that flows through major cities, such as Daegu in Gyeongbuk and Busan in Gyeongnam. It is used as a drinking water source for 10 million South Korean population. The mainstream of Nakdong River basin area is approximately $25 \%$ of the Korean territory, and the total length is approximately $520 \mathrm{~km}$ [1]. After the completion of the Nakdong River Estuary Bank in October 1987, the downstream flow has been stagnant, and the accelerated eutrophication due to a considerable amount of nutrient salts (e.g., industrial and domestic waste water from major cities in the upper and middle portions of the Nakdong River) has caused the increase in the standing crop of phytoplankton and the change in species composition. Every year, the growth of blue-green algae during summer and diatoms during winter has resulted in considerable difficulty with using water resources [2-3]. Among the water pollution in Nakdong River, the most serious issue is the eutrophication in the lower basin due to the combination of unprocessed nutrient salts (e.g., nitrogen and phosphorus) in the upstream. Phosphorus is a key limiting factor, and if its concentration is $0.035 \mathrm{mg} / \mathrm{L}$ or higher, eutrophication, such as an algae outbreak, can happen anytime depending on climate change and hydraulic conditions. Due to the effect of the point source pollutant, the total phosphorus in a river continues to be mixed regularly, and during rainfall, a higher concentration of phosphorus is mixed immediately to the river from the cumulated non-point source pollutant in the basin, thereby causing the eutrophication in the river [4-6].

Eutrophication is a change in the water ecosystem as the increase of nutrient salts in the water, mixed from inside or outside the system by natural or man-made causes, rapidly amplifies the production of phytoplankton, which is the primary producer in the water system. External loading is caused by the nutrient salts produced from the point or non-point source pollutants mixed in the reservoir, while internal loading is the increase of loading in the water system due to the nutrient salts that were eluted from the polluted sediments in the reservoir [7-10]. Although the management of non-point source pollutants has been rather negligent, as they have unspecified emission points and they are mostly
This is an Open Access article distributed under the terms of the Creative Commons Attribution Non-Commercial License (http://creativecommons.org/licenses/by-nc/3.0/) which permits unrestricted non-commercial use, distribution, and reproduction in any medium, provided the original work is properly cited.

Copyright (C) 2018 Korean Society of Environmental Engineers
Received May 23, 2017 Accepted December 18, 2017

${ }^{\dagger}$ Corresponding author

Email: bdlee@uu.ac.kr

Tel: +82-54-760-1702 Fax: +82-54-760-1179

ORCID: 0000-0002-0792-1924 
influenced by weather, geological, and topological conditions, the artificial control is difficult and the pollutant loading of the non-point source pollutants, which are occupying up to 605 of the total pollutant loading in the water system, is larger than that of the point source pollutants, thereby having a huge impact on water quality. Controlling non-point source pollutants has emerged as an important measure to the improvement of water quality [11-12].

The Ministry of Environment also determines that, while the water quality after the Four Major Rivers Project is affected by internal loading due to the stagnant waters, 70 to $80 \%$ of water concentration is due to external mixing, and the decline of the distribution rate of sewage, lack of collection pipelines, decline of the water processing rate, and lack of control of the non-point source pollutants are found to be the causes of external mixing. Therefore, it is believed that the water quality control in the primary and secondary tributaries mixed with the mainstream of the four major rivers is crucial, and the subsequent water quality management measures are urgently required.

As a result, this study identified the water concentration and properties of tributaries mixed with Nakdong River by determining the correlation among the water quality factors and water quality properties in key tributaries at the mid-lower portion of the Nakdong River basin. Furthermore, the correlational influence index was analyzed by using the water quality analysis index via the watershed zone in order to evaluate the influence index of the mainstream centered on the loading of each tributary, and ultimately, it aimed to present data for the direction of the water quality management of Nakdong River.

\section{Methods}

\subsection{Target Areas}

Tributaries, which centered on the four artificial weirs in the middle portion of the Nakdong River basin with a loading and flow rate that could influence the mainstream, were selected for the study. In particular, a total of 27 locations, which included 15 in the mainstream of Nakdong River and 12 in Geumho River and its tributaries, were selected. The target locations of the study are shown in Fig. 1.

\subsection{Sampling and Storage}

Sampling was conducted once a month from January to December 2015.

Samples were regularly collected quarterly and monthly, as well as during normal and dry seasons. The flow rate and water quality were measured at identical locations, considering the behavioral analysis of the pollutants and the correlation between water quality and flow rate. Meanwhile, grab sampling was used for the river water. Based on the official testing method, the analysis focused on BOD, COD, TOC, Chl-a, T-N, and T-P, while $2 \mathrm{~L}$ and $4 \mathrm{~L}$ water sampling bottles were used as the containers for the samples, which were stored in a cold and dark place at $4^{\circ} \mathrm{C}$ after sampling until the analysis.

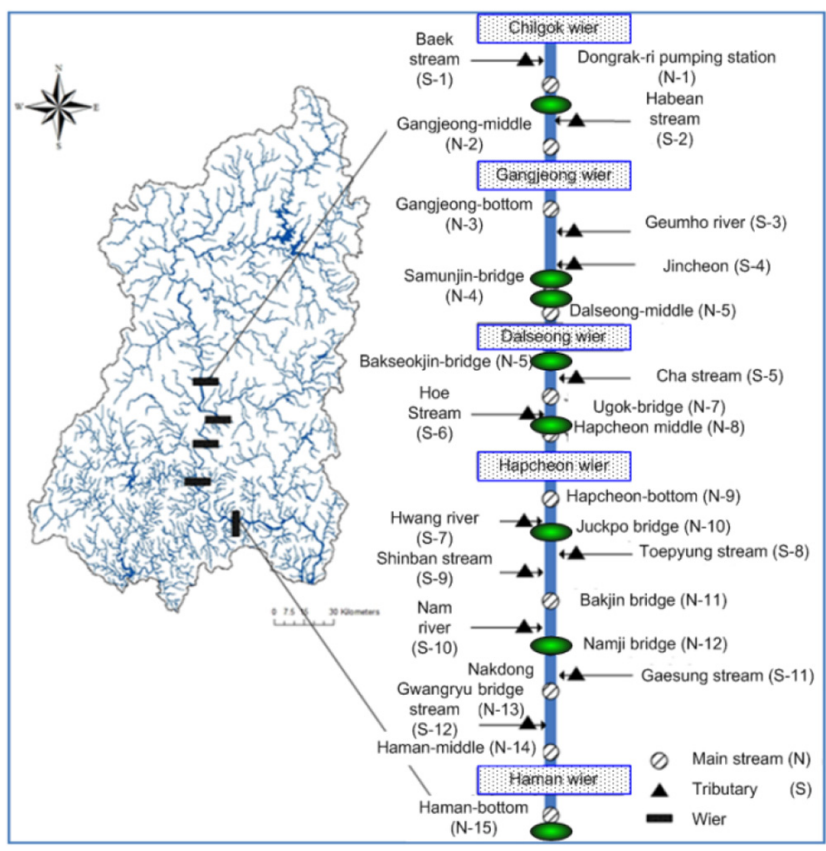

Fig. 1. The location of the weirs downstream Nakdong River basin.

\subsection{Index Assessment}

\subsubsection{The basic theory of the index analysis}

This study aimed to analyze the correlations between the mainstream and tributaries by using the cluster analysis results. In principle, cluster analysis converts the property variables of the target objects into the distance of similarity and clusters objects with the distance of similarity that is relatively close to the same group. In general, the smaller the relative distance, the larger the similarity and vice versa. The cluster analysis results showed that the lower Nakdong River basin and the region with mixed tributaries that have a similar water quality to that of the mainstream of Nakdong River were grouped together. Since it appears that the worsened pollution in the tributaries had a huge impact on the pollution of the mainstream, it is determined that external loading would have a greater impact on the pollution of the mainstream of Nakdong River than internal loading. The study selected the index assessment items from the principal component analysis (PCA) results.

PCA determines the number of dimensions for a more accurate analysis by reducing the dimensions of the calculated principal components, and by using a varimax rotation, which is an orthogonal rotation method. The number of factors among the extracted minimal factors is determined, so as to represent the eigenvalue of the factors and the water quality influence rate.

The factor analysis of the Nakdong River water system (downstream of Chilgok Weir to Haman Weir) showed that the first factor was $22.063 \%$, the second factor was $15.361 \%$, and the third factor was $11.747 \%$. The cumulative sum of the factors, including the fourth, fifth, and sixth factors, was $71.559 \%$.

In the first factor, the factor analysis score for BOD, COD, TOC, Chl-a, and T-P was relatively high, while in the second factor, the factor analysis score of T-N and NO3-N was high. The factor 
analysis results showed that BOD, COD, TOC, Chl-a, T-N, and T-P are correlated as water quality indexes [13]. Based on the factor score results from the PCA, a total of 6 water quality items were selected for the index assessment items. In order to conduct the loading-based index assessment, a total of 7 items, including the flow rate, were considered to be the target index assessment items.

In the index analysis, the inflow of the mid-lower portion of the Nakdong River basin (N1) was divided by the outflow (N2), and the percentage of its result was used to calculate the ratio of the mainstream to each tributary.

$$
\text { Rate of change }( \pm)=100-\left(\frac{N 1}{N 2} \times 100\right)
$$

The rate of change from the mainstream is shown in Eq. (1), wherein the discharging mainstream (N2) is $100 \%$, while the increase rate is calculated by adding or subtracting the ratio of N2 to the tributary.

Based on the indicators in the index, the derived increase rate is used to calculate the data of the index assessment indicators for the measurement and assessment.

\subsubsection{Calculation of the index indicators and percentage}

In creating the indicators, the data are divided into basic monitoring data and processed data. The basic monitoring data are measured data or statistics, while the processed data are the basic monitoring data, which are adjusted to meet the analysis objectives. Specific indicators are the data defined as indicators, while key indicators are those selected from the data and used as indicators [14].

Composite indicators use two or more data to define the indicators. They express more clearly the properties that the data may not express or do so vaguely.

This study define data by using two or more items, thereby creating indicators based on composite indicators, and calculating the index by using the increased rate derived from each tributary. The derived index is the standard by which to quantify the relative influence, and depending on the difference before and after the tributary mixing, up to 5 scores ( \pm 1 for $\pm 10 \%$ to \pm 5 for $\pm 50 \%$ ) were assigned to each item in order to calculate the score by considering \pm 5 as the standard deviation of each item.

The index percentage used the index of each tributary by item based on the index calculation method. Moreover, a sum of indexes was calculated by the obtained indexes. In calculating the total sum, the absolute value of the indexes of each tributary by item was used.

The index percent of the tributaries was derived by calculating the ratio of the sum of each tributary to the sum of the indexes that was derived above.

\section{Results and Discussion}

\subsection{Cluster Analysis}

To examine the necessity of the influence index analysis of tributaries, the study conducted a cluster analysis using the factor

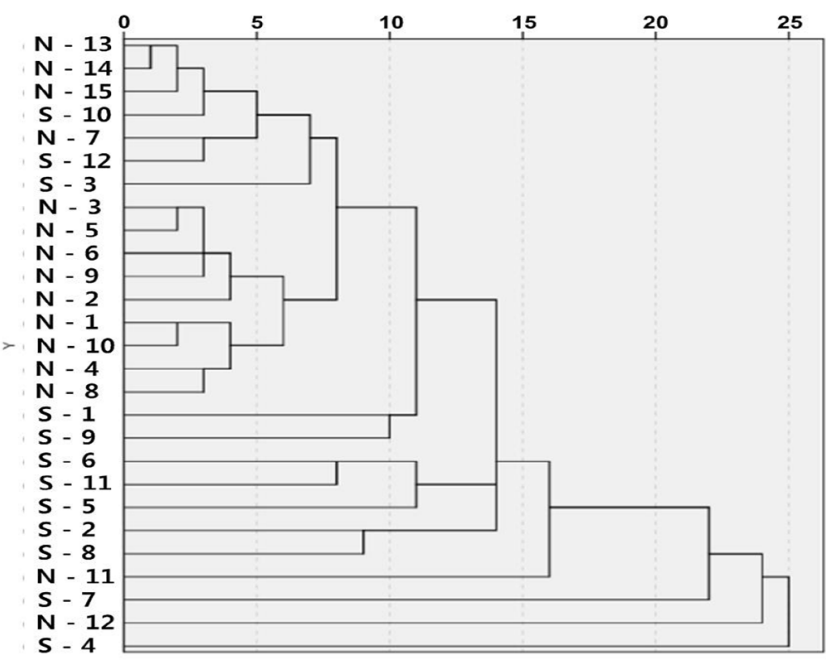

Fig. 2. Cluster analysis by water quality indicators (2015).

scores from the PCA. As shown in Fig. 2, the analyzed results were illustrated in dendrogram so as to clearly demonstrate the difference in water quality among water quality factors by having them the similar influence to water quality fluctuations from the lower Chilgok Weir to Haman Weir by location and by month.

In general, the smaller the relative distance, the larger the similarity and vice versa. The cluster analysis on the locations showed two groups that were clustered and one group that was not clustered. N-13, N-14, N-15, S-10, N-7, S-12, S-3, N-3, and N-5 were included in Group 1 with similar water quality, while N-3, N-5, N-6, N-9, $\mathrm{N}-2, \mathrm{~N}-1, \mathrm{~N}-10, \mathrm{~N}-4$, and N-8 were included in Group 2 with similar water quality. Group 1 clustered the mainstream of the lower Nakdong River basin and locations in which the water quality of the mixing tributary was similar to that of the mainstream, while Group 2 clustered most of the upstream areas of the mainstream. Meanwhile, S-1, S-9, S-6, S-11, S-5, S-2, S-8, N-11, S-7, N-12, and S-4 were not clustered. This result from the cluster analysis showed that most of the tributaries with severe pollution, such as Geumho River, Jincheon-cheon River, Topyeong-cheon River, and lower Gangjeong-Goryeong Weir, were not clustered, and locations that increase pollution among the target locations in Nakdong River were the locations in which these unclustered tributaries were mixed to the mainstream, thereby resulting in a huge impact on the mainstream of Nakdong River. It is believed that for the continuous management of the tributaries, management techniques, such as setting up priorities, would be required, and this study aims to examine these via the Influence Index Assessment.

\subsection{Change of Water Quality by Item}

\subsubsection{Change of water quality by organic matter}

Fig. 3, Fig. 4, and Fig. 5 showed the seasonal variation of BOD and COD concentration based on the flow distance in the mid-lower portion of the Nakdong River basin.

The BOD concentration increased at the upstream location from the pumping station in Dongrak-ri (N-1) to Samunjingyo Bridge $(\mathrm{N}-4)$. This was consistent from Dalseong Weir (N-5), which is 


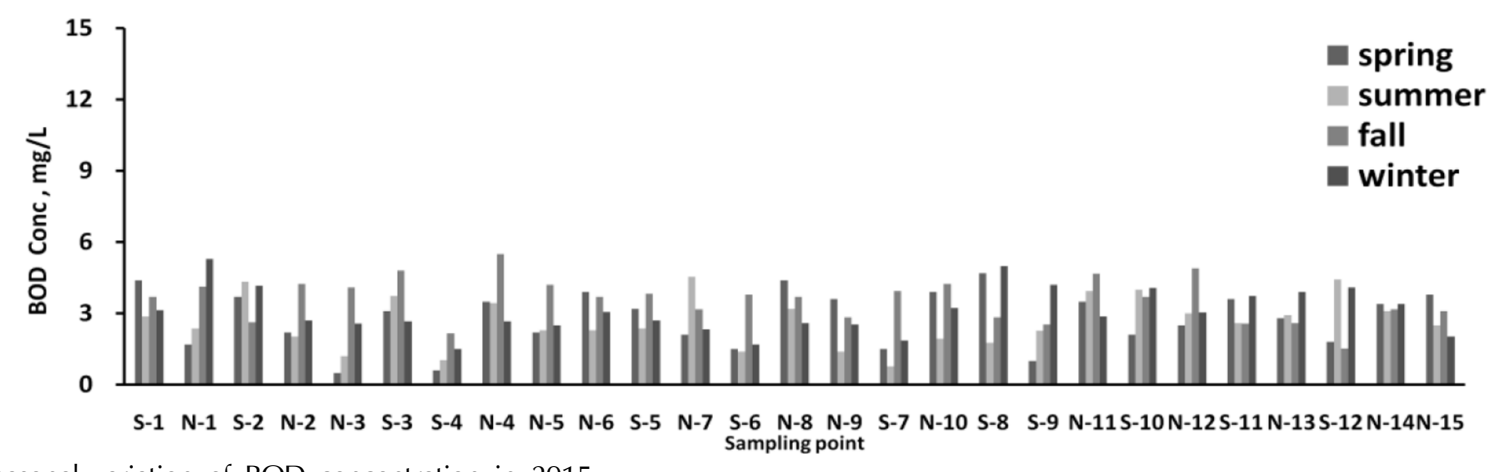

Fig. 3. Seasonal variation of BOD concentration in 2015 .

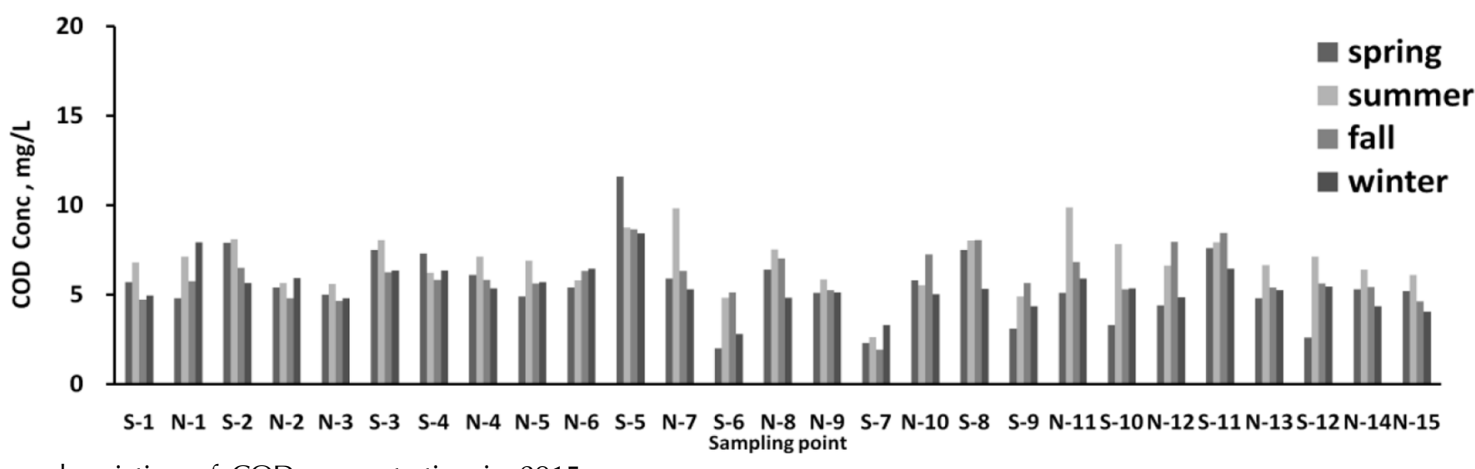

Fig. 4. Seasonal variation of COD concentration in 2015.

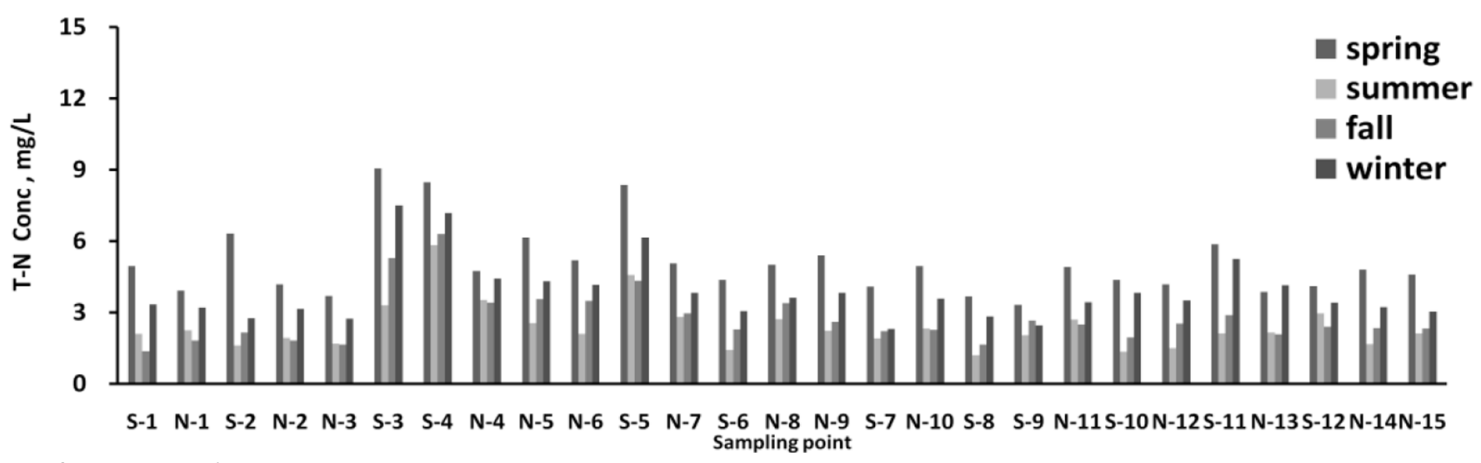

Fig. 5. Seasonal variation of T-N concentration in 2015 .

the midstream, to Bakjingyo Bridge (N-11), which is downstream. This is due to the high BOD concentration of $4.8 \mathrm{mg} / \mathrm{L}$ mixed at the Geumho River location (S-3) and $5.5 \mathrm{mg} / \mathrm{L}$ at Samunjingyo Bridge (N-4), which is the mainstream. The BOD was likely to increase during summer at Jeokpyo Bridge (N-10), which is the midstream, due to the mixing of a high BOD concentration of $5.7 \mathrm{mg} / \mathrm{L}$ at Hwang River (S-7) during summer, thereby leading to a higher BOD concentration of $7.0 \mathrm{mg} / \mathrm{L}$ at Jeokpyo Bridge (N-10).

The BOD concentration by season at most locations, in which tributaries are mixed, showed that the water quality of the mainstream is directly and easily affected by that of the tributaries. In particular, the overall BOD concentration at Geumho River (S-3) had a huge effect on the mainstream, and the increase of BOD concentration at the (S-3) location during summer and winter greatly influenced the water quality of the mainstream. The season- al variation of BOD concentration was generally consistent in the upstream and downstream of Nakdong River, as compared to that of the tributaries.

The seasonal variation of COD concentration became somewhat higher and with a more stable variation width than that of the BOD concentration. As for the variation of COD concentration by location, Cha-cheon River (S-5), which is located at the lower portion of the Dalseong Weir, showed a high concentration of $11.6 \mathrm{mg} / \mathrm{L}$ during spring and a similar concentration during the other three seasons. The average COD concentration of Cha-cheon River (S-5) was $9.37 \mathrm{mg} / \mathrm{L}$, and its influence on the mainstream water quality was higher than the other tributaries at $61.0 \%$. The COD concentration of Geumho River (S-3), which is located at the middle portion of Nakdong River, was high during summer at $8.1 \mathrm{mg} / \mathrm{L}$, while the average COD concentration was $7.05 \mathrm{mg} / \mathrm{L}$, 
and the influence on the mainstream water quality was $58.4 \%$. The COD concentration of Gyeseong-cheon River (S-11), which is located at the lower portion of Nakdong River, was high during fall at $8.0 \mathrm{mg} / \mathrm{L}$, and the average COD concentration was 7.62 $\mathrm{mg} / \mathrm{L}$, and the influence on the mainstream water quality was $56.1 \%$ While there are some differences in the pattern of the mixing to the mainstream depending on the mixing of small streams to tributaries and weather conditions, the variation of COD concentration in tributaries in 2015 were generally stable. In this result, the concentration fluctuation of TOC and Chl-a was similar to that of the organic matter so that TOC and Chl-a were discussed only with regard to the load material balance.

\subsubsection{T-N and T-P changes}

Fig. 6 and Fig. 7 showed the seasonal nutrient salts variation based on the flow distance of the mid-lower portion of the Nakdong River basin. Overall, the T-N concentration during spring and summer was very high. It is believed that due to these dry seasons, the flow rate is considerably lower than the other seasons, and the T-N concentration in the water system tends to increase.

The seasonal variation of T-N concentration at Geumho River (S-3), which is located at the middle portion of Nakdong River, was high during spring and winter at $9.1 \mathrm{mg} / \mathrm{L}$ and $7.5 \mathrm{mg} / \mathrm{L}$, respectively. The average T-N concentration was high at 6.28 $\mathrm{mg} / \mathrm{L}$, and the influence on the mainstream was $72.0 \%$, which is higher than the other tributaries. Next, the spring and winter T-N concentration of Cha-cheon River (S-5), which is located at the mid-lower portion of Nakdong River, was $8.4 \mathrm{mg} /$ and $6.2 \mathrm{mg} / \mathrm{L}$, respectively, while the average $\mathrm{T}-\mathrm{N}$ concentration was $5.86 \mathrm{mg} / \mathrm{L}$, and the influence on the mainstream was $61.0 \%$. The T-N concentration of Gyeseong-cheon River (S-11), which is located at the lower portion of Nakdong River, was high during spring and winter at $5.9 \mathrm{mg} / \mathrm{L}$ and $5.3 \mathrm{mg} / \mathrm{L}$, respectively, while the average T-N concentration was $4.04 \mathrm{mg} / \mathrm{L}$, and the influence on the mainstream water quality was $57.9 \%$.

The seasonal change of water quality by nitrogen in 2015 showed that it was higher during spring than in the other seasons, and the influence of Geumho River (S-3), which is located at the middle portion of Nakdong River, was at the highest on the mainstream.

The T-P concentration of Topyeong-cheon River (S-8), which is located at the lower portion of Nakdong River, was high during summer at $0.18 \mathrm{mg} / \mathrm{L}$, while the average T-P concentration was $0.14 \mathrm{mg} / \mathrm{L}$, and the influence on the mainstream water quality was high at $73.4 \%$.
The T-P concentration of Geumho River (S-3), which is located at the lower portion of Nakdong River, was high during summer at $0.11 \mathrm{mg} / \mathrm{L}$, while the average T-N concentration was $0.09 \mathrm{mg} / \mathrm{L}$, and the influence on the mainstream water quality was $69.8 \%$.

The seasonal variation of T-P concentration in 2015 was generally consistent, and the concentration was high at Geumho River (S-3), which is located at the middle portion of Nakdong River, and Topyeong-cheon River (S-8), which is located at the lower portion of the Nakdong River tributary. In addition, the influence of the Topyeong-cheon River (S-8) on the mainstream was the highest among the tributaries.

\subsection{Load Assessment}

\subsubsection{Variation of BOD and COD load}

Fig. 7 and Fig. 8 showed the seasonal variation of BOD and COD loads based on the flow distance in the mid-lower portion of the Nakdong River basin.

The loads were calculated by the discharge of the mainstream and tributaries of the Nakdong River basin, which was compared to the measured discharge taken from the data of the Nakdong River Flood Control Office and the Water Information System of the Ministry of Environment.

The seasonal variation of the BOD load in 2015 was similar to Geumho River and Jincheon-cheon River (S-3 + S-4) in the middle portion of the Nakdong River basin, and it was higher during spring and summer at $10.215 \mathrm{~kg} / \mathrm{d}$ and $10.107 \mathrm{~kg} / \mathrm{d}$, respectively. A load of tributaries mixed at Geumho River and Jincheon-cheon River was $46.1 \%$, thereby showing a considerably higher effect on the mainstream when compared to the load mixed from the upstream of Nakdong River.

This result shows that the water quality of the lower portion of Gangjeong-Goryeong Weir is degraded by the external loading mixed from Geumho River and Jincheon-cheon River.

It showed that the large discharge of Geumho River (S-3) in 2015 affected the concentration and load of the mainstream. The COD load during summer at Geumho River and Jincheon-cheon River (S-3 + S-4) was higher at $24.868 \mathrm{~kg} / \mathrm{d}$, and the COD load of the tributaries contributing to the mainstream was higher at $40.9 \%$.

It was determined that similar to the BOD load, the COD load of Geumho River and Jincheon-cheon River has a huge influence on the mainstream; therefore, measures to reduce the external loading via the tributaries would be required.

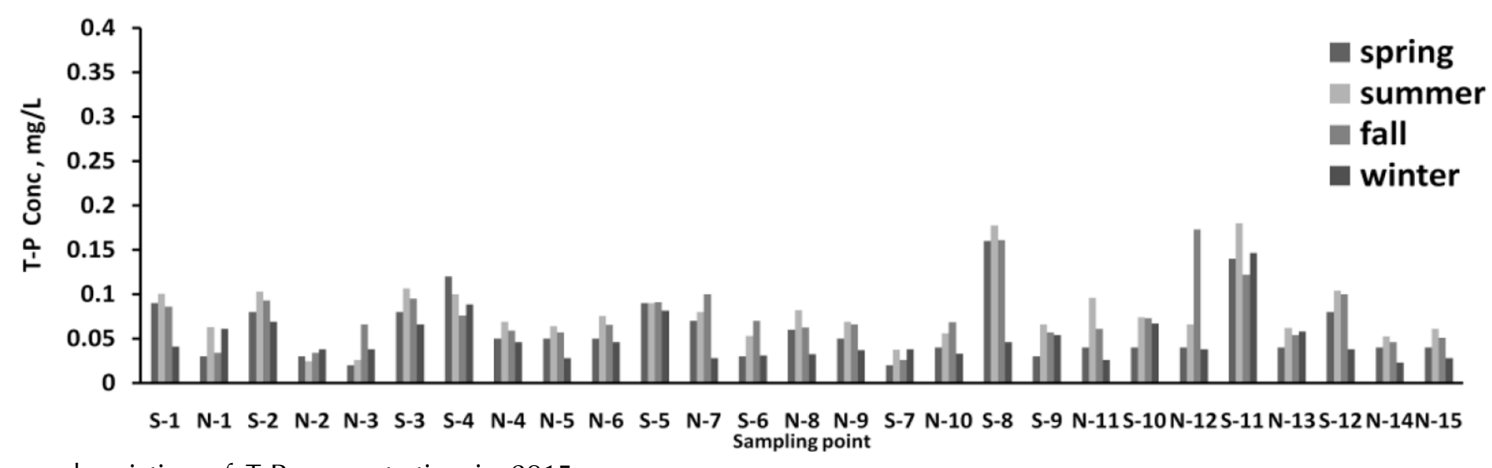

Fig. 6. Seasonal variation of T-P concentration in 2015. 


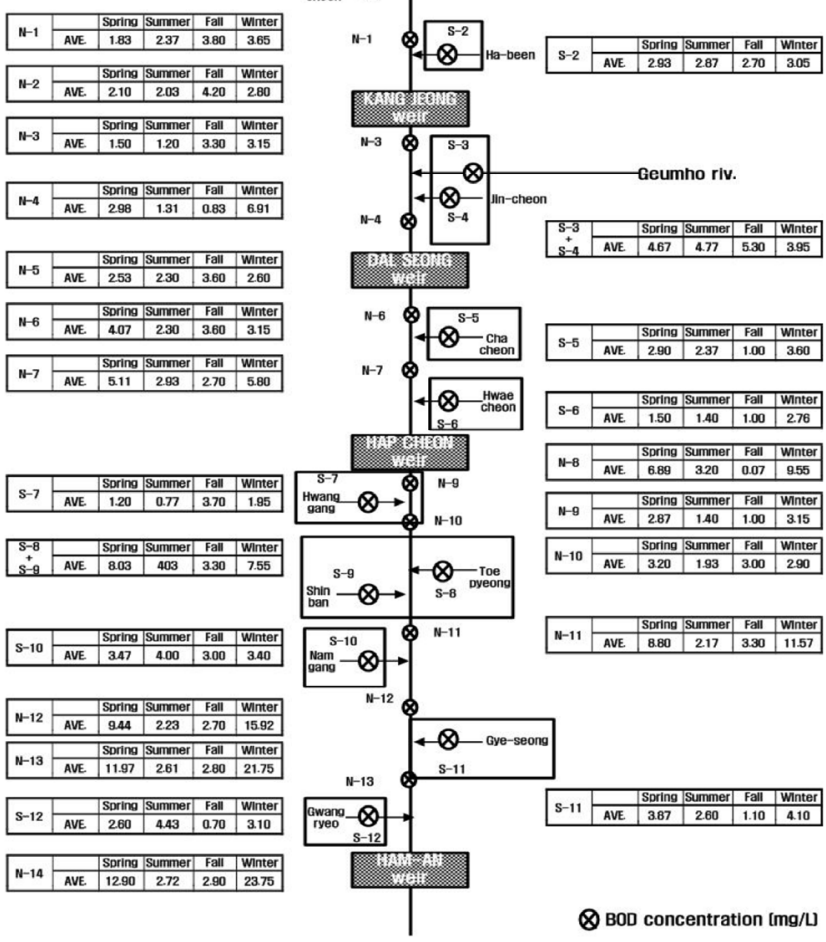

Fig. 7. Seasonal variation of BOD loads in 2015.
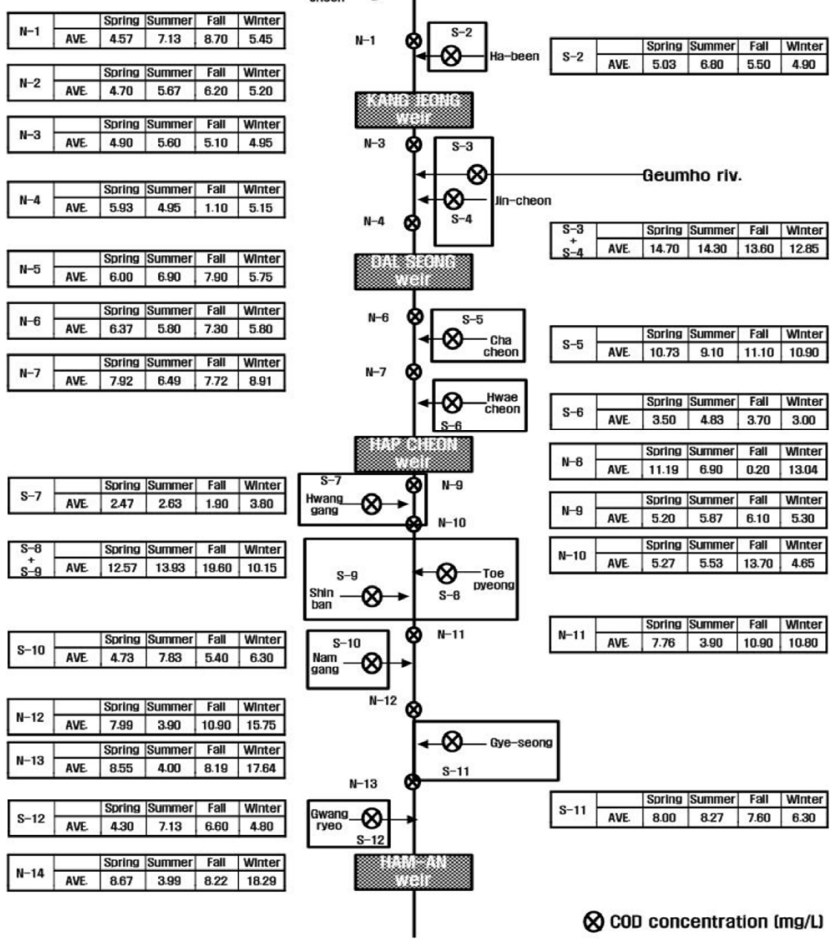

Fig. 8. Seasonal variation of COD loads in 2015.

\subsubsection{Variation of TOC and Chl-a loads}

Fig. 9 and Fig. 10 showed the seasonal variation of TOC and Chl-a loads based on the flow distance in the mid-lower portion of the Nakdong River basin.

The seasonal TOC load at Geumho River and Jincheon-cheon River (S-3 + S-4), which are located at the middle portion of the Nakdong River basin, was relatively similar in all seasons. However, during summer, it was at the highest with $26.186 \mathrm{~kg} / \mathrm{d}$, and the load influence on the mainstream was $43.1 \%$. The TOC load of Hwang River (S-7), which is located at the lower portion of Nakdong River, was high during summer and winter at 12.649 $\mathrm{kg} / \mathrm{d}$ and $10.468 \mathrm{~kg} / \mathrm{d}$, respectively. The load influence on the mainstream was $14.5 \%$. The TOC load of Nam River (S-10) was high during spring and summer at $16.675 \mathrm{~kg} / \mathrm{d}$ and $22.411 \mathrm{~kg} / \mathrm{d}$, respectively, while the load influence on the mainstream was $12.3 \%$.

Therefore, the TOC load influence of Geumho River and Jincheon-cheon River $(\mathrm{S}-3+\mathrm{S}-4)$ was higher than the other tributaries.

The Chl-a load of Nakdong River and Jincheon-cheon River (S-3 + S-4), which are located at the middle portion of the Nakdong River basin, was considerably higher during summer than in the other seasons at $107.094 \mathrm{~kg} / \mathrm{d}$, while the load influence on the mainstream was high at $48.2 \%$. In addition, the Chl-a load of Nam River (S-10), which is located at the lower portion of Nakdong River, was high during summer at $241.663 \mathrm{~kg} / \mathrm{d}$, while the load influence on the mainstream was $27.3 \%$.
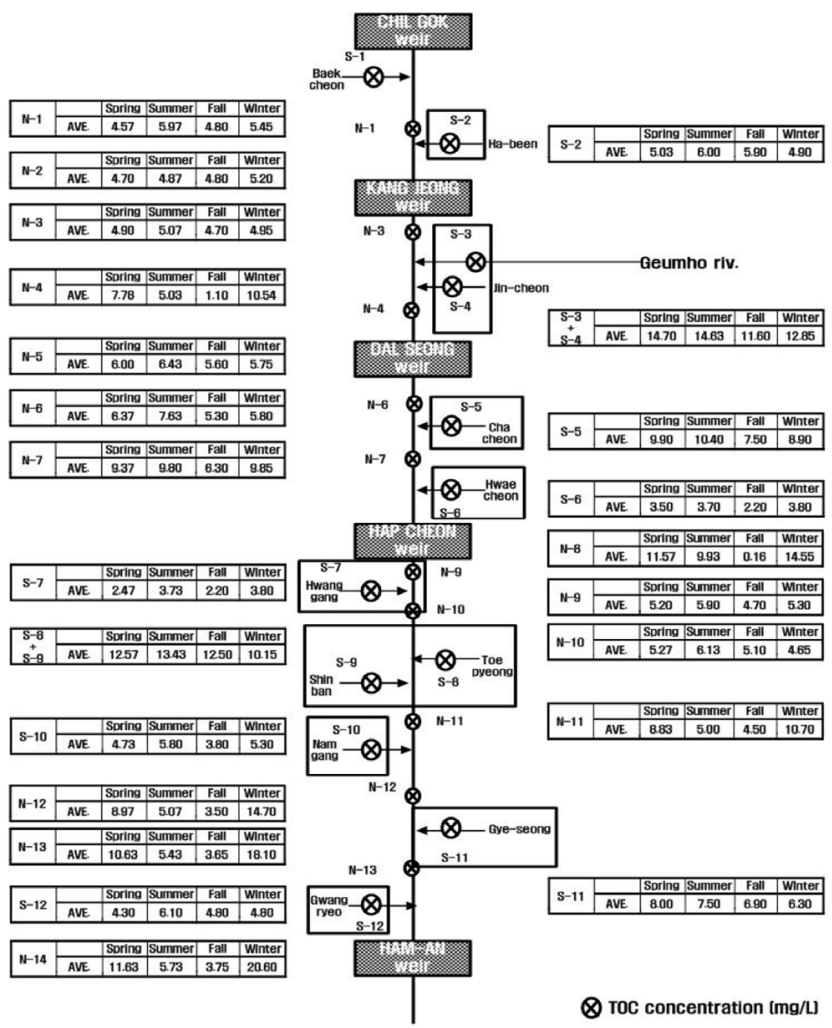

Fig. 9. Seasonal variation of TOC loads in 2015. 


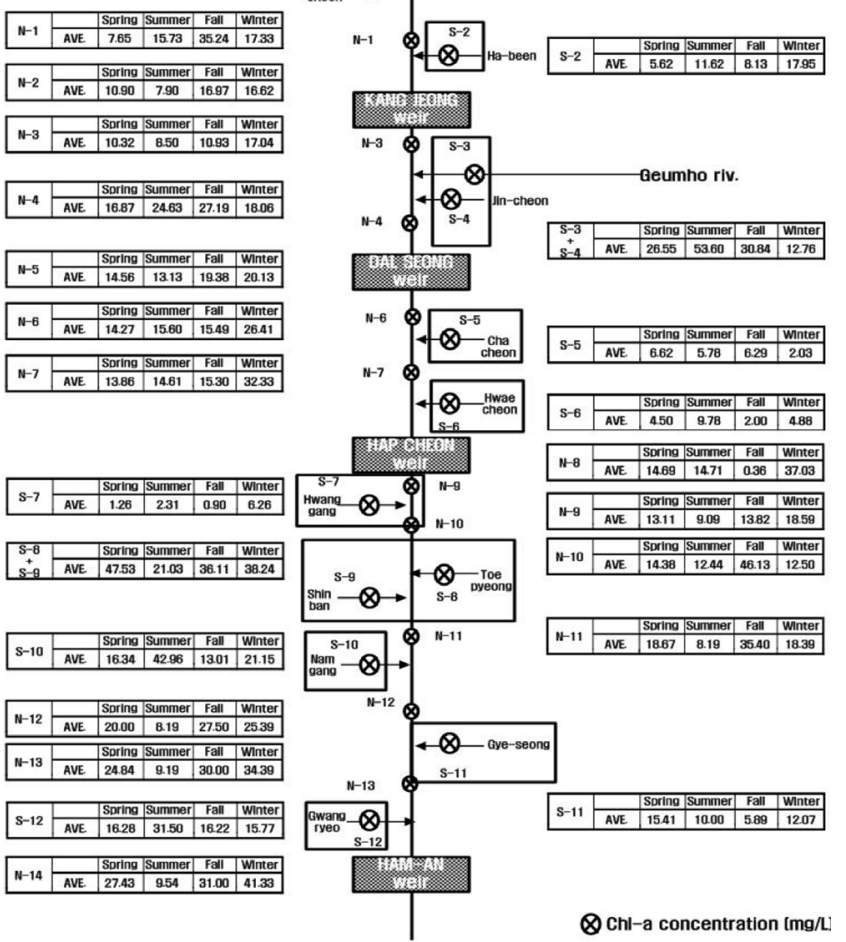

Fig. 10. Seasonal variation of chlorophyll-a loads in 2015.

Therefore, the Chl-a load at Geumho River and Jincheon-cheon River, which are located at the middle portion of the Nakdong River basin, and Nam River, which is located at the lower portion of the Nakdong River basin, were relatively higher than the other tributaries. Therefore, it is believed that measures to reduce the Chl-a concentration in tributaries are required.

\subsubsection{Variation of $\mathrm{T}-\mathrm{N}$ and T-P loads}

Fig. 11 and Fig. 12 showed the seasonal variation of nutrient salts based on the flow distance in the mid-lower portion of the Nakdong River basin.

The T-N load of Nakdong River and Jincheon-cheon River (S-3 + S-4), which are located at the middle portion of the Nakdong River basin, was high during winter at $27.930 \mathrm{~kg} / \mathrm{d}$ and the load influence on the mainstream was high at $51.8 \%$. The T-N load of Hwang River (S-7), which is located at the lower portion of Nakdong River, was high during winter at $6.893 \mathrm{~kg} / \mathrm{d}$ and the load influence on the mainstream was $15.9 \%$. While the T-N load of Nam River (S-10) was similar in all seasons, spring was the highest at $10.747 \mathrm{~kg} / \mathrm{d}$ and the load influence on the mainstream was $11.9 \%$.

The T-P load of Nakdong River and Jincheon-cheon River (S-3 + S-4), which are located at the middle portion of the Nakdong River basin, was high during summer at $418 \mathrm{~kg} / \mathrm{d}$ and the load influence on the mainstream was considerably high at $50.3 \%$. Similarly, the T-P load of Nam River (S-10), which is located at the lower portion of Nakdong River, was high during summer at $294 \mathrm{~kg} / \mathrm{d}$ and the load influence on the mainstream was $23.0 \%$.
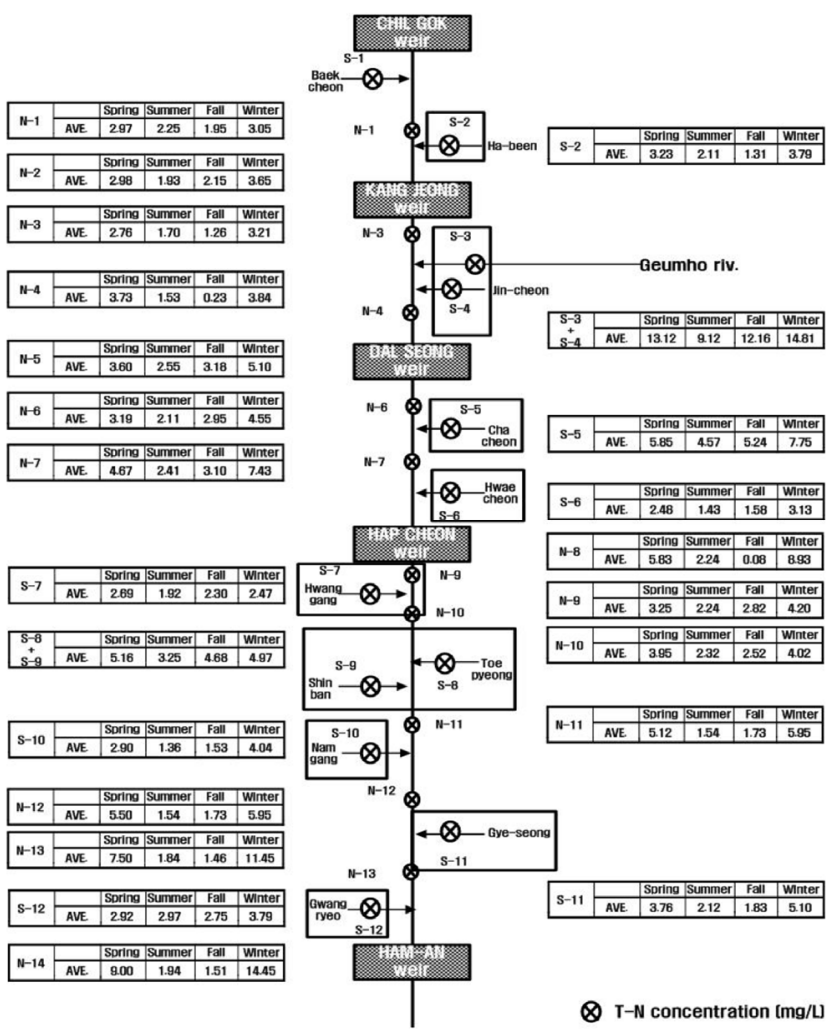

Fig. 11. Seasonal variation of T-N loads in 2015.

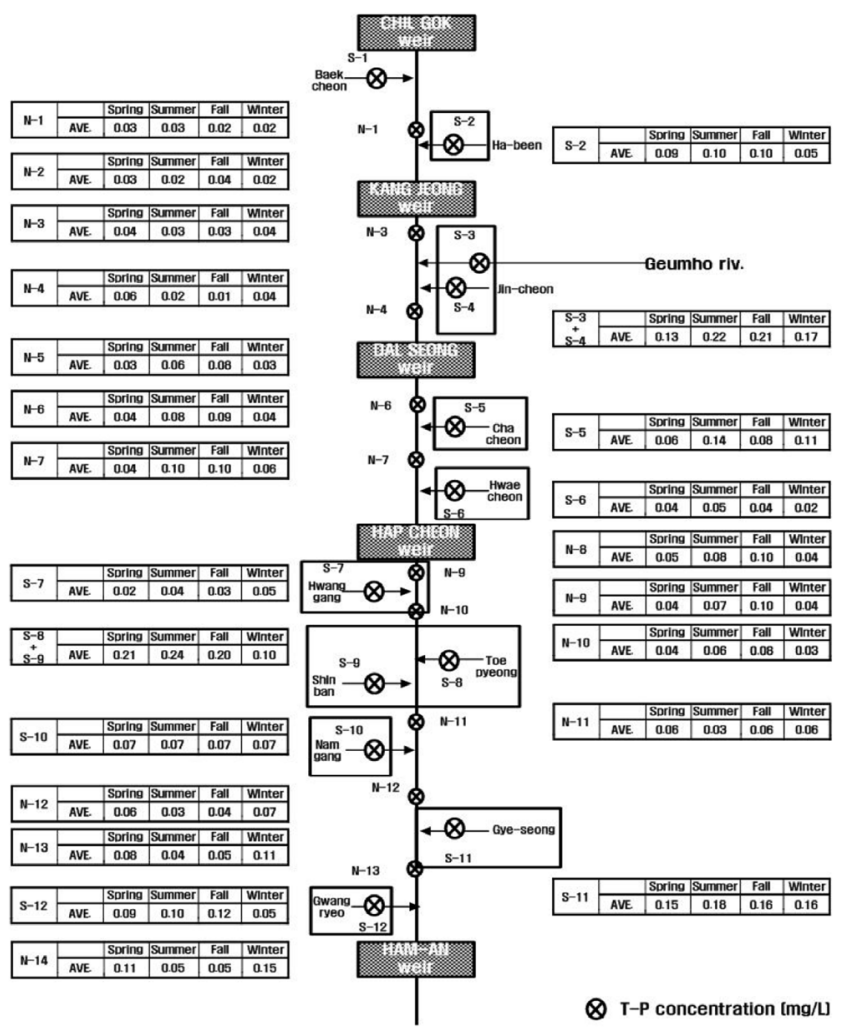

Fig. 12. Seasonal variation of T-P loads in 2015. 
Table 1. Index Analysis by Water Quality Item Average Load

\begin{tabular}{|c|c|c|c|c|c|c|c|c|c|}
\hline \multirow{2}{*}{ Parameters } & \multicolumn{9}{|c|}{ Tributary Spot (2015) } \\
\hline & S-2 & $S-3+S-4$ & S-5 & S-6 & S-7 & $S-8+S-9$ & S-10 & S-11 & S-12 \\
\hline BOD & -1 & 5 & 3 & 3 & 4 & 5 & 3 & 2 & 1 \\
\hline COD & -1 & 4 & 2 & 3 & 3 & 4 & 3 & 1 & 1 \\
\hline TOC & -1 & 5 & 3 & 3 & 3 & 5 & 3 & 2 & 1 \\
\hline Chl-a & -3 & 5 & -2 & 2 & 4 & 3 & 3 & 3 & 1 \\
\hline $\mathrm{T}-\mathrm{N}$ & 1 & 4 & 3 & 2 & 2 & 3 & 3 & 3 & 2 \\
\hline $\mathrm{T}-\mathrm{P}$ & -1 & 3 & 2 & 1 & 1 & 3 & 3 & 3 & 3 \\
\hline Flow & 1 & 4 & 1 & 2 & 3 & 3 & 2 & -1 & -1 \\
\hline Total & -5 & 31 & 12 & 16 & 20 & 26 & 20 & 13 & 8 \\
\hline Percentage & -3.3 & 20.5 & 7.9 & 10.6 & 13.2 & 17.2 & 13.2 & 8.6 & 5.3 \\
\hline
\end{tabular}

The T-P load of Hwang River (S-7), which is located at the lower portion of Nakdong River, was high during summer and winter at $122 \mathrm{~kg} / \mathrm{d}$ and $130 \mathrm{~kg} / \mathrm{d}$, respectively, and the load influence on the mainstream was $14.7 \%$.

As a result, the load influence of Geumho River and Jincheoncheon River was high, thereby requiring measures to reduce the nutrient salts in the tributaries.

\subsection{Index Analysis}

\subsubsection{Index assessment by average load}

Loads of tributaries mixed at the mid-lower portion of the Nakdong River basin were divided into 7 water quality items, and the corresponding indexes were calculated, as shown in Table 1.

The index analysis of the average load showed that the index sum of Geumho River and Jincheon-cheon River (S-3 + S-4) was the highest at 31 . In addition, the comparison of the indexes by item showed that BOD, TOC, and Chl-a, which were at 5 , were higher than the other items, and T-P was the lowest at 3. Next, the index sum of Topyeong-cheon River and Shinban-cheon River (S-8 + S-9), and that of Nam River (S-10) were higher at 26 and 20, respectively. However, the BOD and TOC index of Topyeong-cheon River and Shinban-cheon River (S-8 + S-9) was highest at 5, while the BOD and TOC index of Nam River (S-10) was low at 2. The index of the other 6 items was consistent at 3 . The comparison of the percentage of each tributary index to the index sum showed that Geumho River and Jincheon-cheon River (S-3 + S-4) have the highest percentage at $20.5 \%$, followed by Topyeong-cheon and Shinban-cheon (S-8 + S-9) at $17.2 \%$.

Based on the index analysis of the average loads, it was determined that the influence of both Geumho River and Jincheon-cheon River (S-3 + S-4), as well as Topyeong-cheon and Shinban-cheon (S-8 + S-9), on the mainstream was higher than the other tributaries.

\subsubsection{Index cumulative percentage}

Each index of the average concentration index analysis in the mid-lower portion of the Nakdong River basin was converted to a percentage (\%) and cumulative percentage (\%), as shown in Table 2.
Table 2. Index Cumulative Percentage Average Load in 2015

\begin{tabular}{ccc}
\hline Location & Percentage (\%) & Cumulative Percentage (\%) \\
\hline S-3 + S-4 & 20.5 & 20.5 \\
S-8 + S-9 & 17.2 & 37.7 \\
S-7 & 13.2 & 51.0 \\
S-10 & 13.2 & 64.2 \\
S-6 & 10.6 & 74.8 \\
S-11 & 8.6 & 83.4 \\
S-5 & 7.9 & 91.4 \\
S-12 & 5.3 & 96.7 \\
S-2 & -3.3 & 100.0 \\
\hline
\end{tabular}

The percentage of Geumho River and Jincheon-cheon River (S-3 + S-4) was highest at $20.5 \%$, followed by Topyeong-cheon and Shinban-cheon (S-8 + S-9) at 17.2\%, Hwang River (S-10) at $13.2 \%$, Hoe-cheon River (S-10), Gyeseong-cheon River (S-11), and Cha-cheon River (S-5). It was determined that, while the concentration at Cha-cheon (S-5) was very high, the percentage was low due to the reduction of the discharge mixed with the tributary. Considering that the influence index is high when the cumulative percentage exceeds $60 \%$, the 4 tributaries from Geumho River and Jincheon-cheon (S-3 + S-4) to Nam River (S-1), have a percentage of $13.2 \%$ and a cumulative percentage of $64.2 \%$, are believed to have a significant impact on the mainstream. Therefore, it is advisable to establish the corresponding measures.

As a result, it is determined that the long-term monitoring and water quality management for the 4 tributaries, Geumho River and Jincheon-cheon River (S-3 + S-4), Topyeong-cheon and Shinban-cheon (S-8 + S-9), Hwang River (S-7), and Nam River (S-10), which showed a higher index ratio, would be required as a priority.

\section{Conclusions}

The analysis of the load material balance revealed that the tributary with the largest influence index was Geumho River (S-3), followed 
by Nam River (S-10). The index assessment showed that Geumho River (S-3) had the largest contribution to the mainstream, as the ratio of its average load to the total load was highest from 19.6 to $20.5 \%$, followed by Topyeong-cheon and Shinban-cheon (S-8 + S-9) at 17.2\%, Nam River (S-10) and Hwang River (S-7) at $13.2 \%$, and in the order of Hoe-cheon River (S-10), Gyeseong-cheon River (S-11), and Cha-cheon River (S-5). As a result, it was found that with $60 \%$ of the cumulative percentage as the basis for the improvement of water quality of the mainstream, long-term monitoring, and water quality management for the 4 tributaries, Geumho River and Jincheon-cheon River (S-3 + S-4), Topyeong-cheon and Shinban-cheon (S-8 + S-9), Hwang River (S-7), and Nam River (S-10), which showed a higher index ratio, would be required as a priority.

\section{Acknowledgments}

This work was supported by the Nakdong River Watershed Management Committee, GBGEC (Gyeongbuk Green Environment Center) and 2016 Yeungnam University Research Grant.

\section{References}

1. Gwak BR, Kim IK. Characterization of water quality in Changnyeong-Haman weir section using statistical analyses. J. Korean Soc. Environ. Eng. 2016;38:71-78.

2. Son HJ. Long-term variations of phytoplankton biomass and water quality in the downstream of Nakdong river. J. Korean Soc. Environ. Eng. 2013;35:263-267.

3. Wang XT, Luo GF, Cao M. Effect of nutrient cycles in tributaries on the transport of nutrient in the three Gorge reservoirs: A case study of coating river. Chinese J. Environ. Sci. 2016;37:2957-2963.
4. Nguyen XQV, Tuan VD, Hojeong K. Impoundments increase potential for phosphorus retention and remobilization in an urban stream. Environ. Eng. Res. 2014;19:175-184.

5. Millar JJ, Payne JP, Ochs CA, Jackson M. Particle-associated and cell-free extracellular enzyme activity in relation to nutrient status of large tributaries of the lower Mississippi river. Biogeochemistry 2015;124:255-271.

6. Robinson C. Review on groundwater as a source of nutrients to the great lakes and their tributaries. J. Great Lakes Res. 2015;41:941-950.

7. Song MY, Jun MS, Lee HD, Jung BS. Study on the traveling route and control method of eutrophication sources in Han river basin. Kyong-Gi Development Institute; 2015. p. 1-111.

8. Pack DH, Han KC, Lee JS, et al. Eutrophication evaluation of mid-lower reaches of Nakdong river. J. Korean Soc. Urban Environ. 2008;8:99-106.

9. Oh KH, Cho YC. Evaluation of contamination level of the sediments from Chusori and Chudong areas in Daechung reservoir. J. Korean Soc. Environ. Eng. 2015;37:277-284.

10. Kim TH, Jung JH, Choi SH, Choi IS, Oh JM. Physicochemical characteristics and nutrient release from sediment in an urban stream. Ecol. Resilient Infrastruct. 2015;2:167-176.

11. Kim H. Effluent trading for water quality improvement: Focusing on point-nonpoint source trading. The Justice; 2011. p. 317-351.

12. Gorme JB, Maniquiz MC, Song P, Kim LH. The water quality of the Pasig river in the city of Manila, Philippines: Current status, management and future recovery. Environ. Eng. Res. 2010;15:173-179.

13. A study on mass balance analysis and water quality management of weir segment. Nakdong River Water System Management Committee; 2015.

14. A study on estimation of comprehensive environmental impact assessment index for development projects. Korea Environment Institute; 2010. 